\title{
AN IMPROVED APPARATUS FOR THE FILTER PAPER ELECTROPHORESIS OF SERUM AND OTHER PROTEINS
}

\author{
BY \\ G. 'T. FRANGLEN \\ From the Medical Unit, University College Hospital Medical School, London
}

(RECEIVED FOR PUBLICATION MARCH 17, 1953)

Since Wieland and Fischer (1948) showed that the ionophoretic separation of amino acids could be effected on filter paper, several different methods of running such electrophoretograms have been described; these have been concerned mostly with the fractionation of serum proteins (Durrum, 1950 ; Flynn and de Mayo, 1951 ; Kunkel and Tiselius, 1951). The types of apparatus used in paper electrophoresis can be divided into two main classes: (a) those in which the paper is horizontal (Cremer and Tiselius, 1950), (b) those in which it forms an inverted V (Durrum, 1950). During investigations on serum and plasma both types were examined in detail. As a result, an apparatus was designed in which protein bands up to $25 \mathrm{~cm}$. in width could be subjected to electrophoresis without distortion. This is considerably wider than has been found possible using other types of apparatus, and increases the range of analyses that can be carried out on the separated fractions. Moreover, in this apparatus, the degree of separation of protein fractions is found to be independent of the position of application of the protein solution to the paper, in contrast to the inverted $V$ type, in which the speed of movement varies with the height of the starting line above the buffer level. Finally a device is incorporated which increases the range of buffers which can be used to maintain a constant $p \mathrm{H}$ over the paper during a long period of electrophoresis.

This method has been used mostly for the electrophoresis of plasma and serum proteins, but it has been found satisfactory for the fractionation of other proteins, including parathyroid extract, insulin, spun milk, and nephrotic urine proteins.

\section{Apparatus}

The Electrophoresis Box.-The apparatus consists of a shallow box $27 \times 25 \times 5.5 \mathrm{~cm}$. made of perspex $0.4 \mathrm{~cm}$. thick (Fig. 1). Four perspex walls parallel to the longest side divide it into five rectangular compartments. These walls are erected symmetrically, the outer pair being $1.5 \mathrm{~cm}$. and the inner pair $3.0 \mathrm{~cm}$. from the side.

Each of the outer compartments (electrode compartments) has two electrodes inserted into it through holes in the side of the box, $0.7 \mathrm{~cm}$. from the bottom. The electrodes in use at present are soft-cored carbon rods $0.6 \times 12.0 \mathrm{~cm}$. To prevent buffer leaking out of the box the electrodes are held in their holes by short rubber sleeves, and are sealed in position with perspex cement. The adjacent compartments (strip compartments) hold the ends of the filter paper. Small lugs on the side of the box support glass rods $4 \mathrm{~cm}$. above the centre of the floor of these compartments. The paper passes over these rods and is stretched horizontally over the centre compartment.

A rubber strip is fixed around the top edge of the box, so that an efficient seal is formed when the lid is put on. This is important as a bad seal usually results in the formation of fronts which are crescent shaped instead of straight. The lid is made of glass $0.5 \mathrm{~cm}$. thick; lids of perspex have not been found satisfactory as they tend to warp and are not heavy enough to seal effectively on to the rubber strip.

Electrical Supply.-A simple circuit using $120 \mathrm{~V}$ dry batteries in series with a milliammeter and the paper strip is satisfactory for most purposes. The voltage is usually adjusted to $120-150 \mathrm{~V}$; this gives a current of $0.15-0.20 \mathrm{~mA} / \mathrm{cm}$. width of paper. In

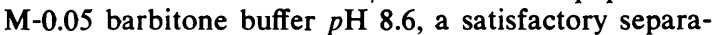
tion of serum proteins is obtained in a 12 to 16 -hour run under these conditions. More rapid separation can be effected by the use of higher potential differences, but the increased heat is liable to distort the electrophoretogram.

Connecting and Levelling Syphons.-Glass syphons (bore diameter $0.3 \mathrm{~cm}$.) filled with buffer solution and hung on the separating partition ensure electrical connexion between the electrode and the strip compartments. Three or four of these connecting syphons are used in each pair of compartments. This method has been found more satisfactory than the use of cotton-wool wicks (Flynn and de Mayo, 1951), as hydrostatic equilibrium between the compartments is more rapidly attained. Another syphon of similar bore (levelling syphon) passes across the centre of 


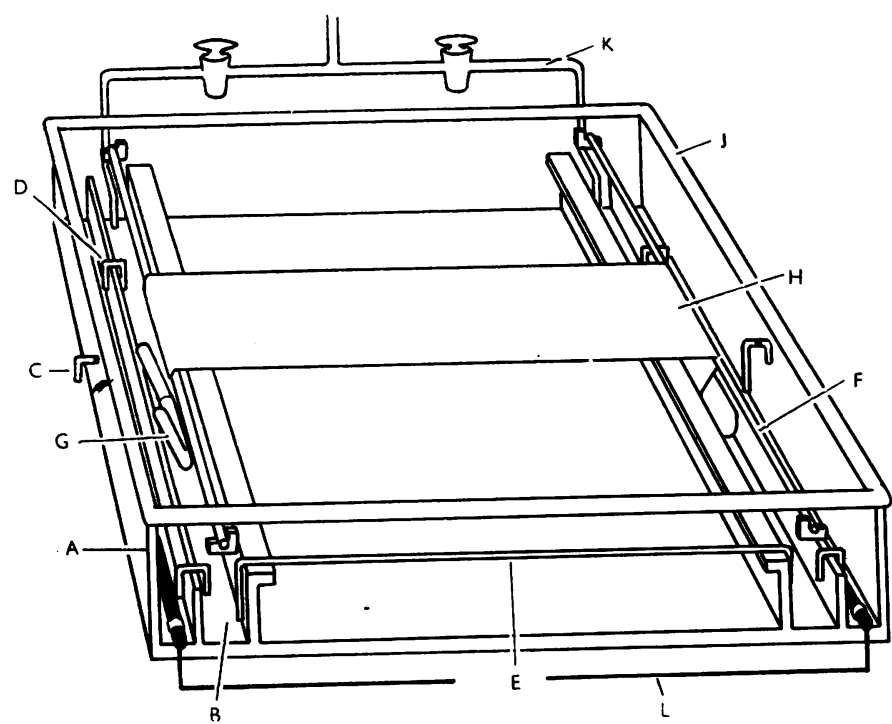

Fig. 1.-Diagram of electrophoresis apparatus. A. Electrode compartment; B. strip compartment; C. outlet siphon; D. connecting siphon; E. levelling siphon; F. filter paper supporting rods; $G$. glass weight $\mathbf{H}$. filter paper in position for electrophoresis; $J$. rubber rim; $K$. buffer inlet; $L$. leads to battery.

the box and connects the two strip compartments. When the current is switched on, this syphon forms an electrical shunt across the two ends of the box, but when the paper is in position the proportion of current passing through this syphon is small and appears to be constant for any one buffer.

Buffer Drip System.-The M-0.05 barbitone buffer, pH 8.6 (Durrum, 1950), commonly employed in this type of work can be used in the apparatus described above with good results. With many other buffers, however, the volume of fluid contained in the compartments is not enough to maintain a constant $p \mathrm{H}$. over the paper. for the duration of the run. The present apparatus includes a device which allows the buffer to be continually renewed so that the $p H$ can be kept constant for as long as is necessary. A 1,000 $\mathrm{ml}$. aspirator bottle placed above the apparatus is connected by glass and rubber tubing to the vertical arm of an inverted T-piece. The horizontal arms include taps and are connected to small glass tubes which lead to the floor of the strip compartments through holes in the side of the box. Buffer contained in the aspirator runs into the strip compartments and causes the buffer already present to overflow through the connecting syphons into the adjacent electrode compartments. After washing along the electrodes it drips out of the apparatus through outlet syphons set in the ends of the box. It is important that the volume of buffer flowing into and out of each side of the apparatus should be equal. The taps, therefore, must be carefully adjusted and the ends of the outlet syphons must be exactly level with each other. The rate of buffer flow from the aspira- tor is controlled by a tunnel clip. To check that the buffer is running, especially at low rates of flow, a simple bubble flowmeter is incorporated in the aspirator.

\section{Experimental}

To obtain good separation of protein fractions it is essential to avoid denaturation of the proteins and to eliminate as far as possible any movement of the bands due to causes other than the flow of electric current through the paper. Besides the many well-recognized factors which cause denaturation, it has been found that the protein solution must not be allowed to come in contact with dry paper as this also produces partial denaturation. Non-specific movement of the protein fractions is produced whenever there is disequilibrium, either in the hydrostatic system of the fluid compartments, or when water vapour is allowed to escape from the apparatus. The technique described has been found to reduce the error due to such movement.

Preparation of the Paper.-Whatman's No. 1 or No. 4 has been found the most satisfactory for general use. Two points should be noted. First, wrinkling of the surface is prevented when the direction of machining of the paper is parallel to the supporting rods rather than at right angles to them. Secondly, in the case of Whatman's No. 1 filter paper, proteins tend to run more evenly on the smooth side of the paper than on the rough. The paper is cut, therefore, so that when it is in position in the apparatus the protein solution can be applied to the smooth side along a line running parallel to the machining. For an apparatus of the dimensions cited above, a suitable length of paper is about $35 \mathrm{~cm}$., and the width can be anything up to $25 \mathrm{~cm}$. Two pairs of pencil lines are drawn on the paper, one pair at the position of the supporting rods (rod lines), another pair between these and parallel to them at the position of the starting band (reference lines). When plasma or serum is electrophoresed in M-0.05 barbitone buffer $p H \quad 8.6$ the reference lines are drawn $0.3-0.5 \mathrm{~cm}$. apart, about $4 \mathrm{~cm}$. from the rod line on the cathode side of the electrophoretogram.

Buffer, $50 \mathrm{ml}$, is put into each of the strip and electrode compartments and sufficient in the centre compartment to flood the floor completely. The large liquid surface produced is important for the maintenance of the humid atmosphere essential for good electrophoretograms. If the buffer has to be renewed continuously during the run the drip is started and adjusted to a suitable rate. The paper is folded along the rod lines and is placed in position on its supporting rods, the ends being loosely tucked 
into the strip compartments so that they drip into the buffer. Spraying the paper to hasten the uptake of buffer is not recommended as this often results in an uneven surface. When the paper is completely soaked, one end is tucked into its final position in its strip compartment with a small glass T-piece, and is weighted down with small, square-bottomed glass $\mathrm{U}$-pieces or with a glass rod. The slack of the paper is taken up from the other end, care being taken to maintain the reference lines parallel to the supporting rods. When the paper has been stretched as tightly as possible, the other end is tucked into its strip compartment and secured by glass weights. The lid is pat on and the box is left for at least 30 minutes before the protein is laid on the paper.

Preparation of the Protein Solution.-The protein solution should be dialysed against buffer before being subjected to electrophoresis. If the solution is prepared from salt-free protein it is usually sufficient to make it up in the buffer, but any undissolved protein must be removed before the solution is electrophoresed. Good electrophoretograms can be obtained from undialysed serum as has been reported by a number of workers, but with plasma dialysis is usually necessary to prevent the fibrinogen fraction from denaturing when it is put on the paper and causing tailing of the other fractions. The strength of protein solution suitable for electrophoresis depends to a large extent on the nature of the proteins in the mixture and on their relative concentrations. Often poor resolution of highly concentrated fractions can be improved by diluting the solution. The extent to which this can be carried is limited by the method used for protein analysis, but when dye methods are used a concentration of 0.2 to $5 \mathrm{~g}$./ $100 \mathrm{ml}$. for each fraction has.been found sàtisfactory.

Application of the Protein Solution to the Paper.The protein solution is applied to the paper with a narrow ribbon of Whatman's No. 1 filter paper. This is cut as long as the width of the electrophoretogram and as wide as the thickness of the protein band to be applied; a generally useful thickness for the latter has been found to be $0.3-0.5 \mathrm{~cm}$. After being damped with buffer, the ribbon is held at each end by forceps and is passed quickly through the protein solution. Alternatively, the solution can be applied to the damp ribbon with a micro-pipette. The excess solution is removed by blotting the rough side of the ribbon on buffer-damped filter paper. Protein solution is applied to the ribbon once again, and after the excess has been removed the smooth side of the ribbon is laid on the strip between the reference lines. When a measure of the endo-electro-osmotic flow is required a spot of dextran solution $(6 \% \mathrm{w} / \mathrm{v})$ is applied to each end of the ribbon when it is in position (Kunkel and Tiselius, 1951). During this process the lid is opened no more than is necessary and is closed down as soon as it is completed. The ribbon is left on for a timed interval, usually nine minutes, at the end of which it is removed. The box is closed and is left a further 10 minutes before the current is switched on. The time necessary for satisfactory separation varies with the protein mixture in question and the buffer in which it is run; for most natural mixtures 12 to 16 hours has been found sufficient for good separation of serum fractions when alkaline buffers have been used. At the end of this time the current is switched off, and the electrophoretogram is removed immediately.

Dyeing of the Protein Fractions.-The electrophoretogram is dried evenly at $105^{\circ}$ for 30 minutes, and then may be dyed in a variety of ways. The azocarmine $B$ method described by Plückthun and Götting (1951) has been found more satisfactory than the naphthalein black method described by Flynn and de Mayo (1951) or the bromophenol blue method of Kunkel and Tiselius (1951). A modification of the bromocresol green method of Robinson and Fehr (1952) has also been used. The electrophoretogram was dyed for 10 minutes in a mixture of $0.2 \%$ $(\mathrm{w} / \mathrm{v})$ bromocresol green (B.D.H.) in industrial ethanol containing $2 \%(\mathrm{v} / \mathrm{v})$ glacial acetic acid. It was washed for 20 minutes in four changes of $2 \%$ $(\mathrm{v} / \mathrm{v})$ acetic acid in water. After drying the coloured bands can be darkened by exposing the electrophoretogram to ammonia fumes. This method appears to be superior to any of those mentioned above for detecting small quantities of protein, but the dark blue is not stable.

\section{Results and Discussion}

Examples of serum and plasma electrophoretograms are shown in Fig. 2. All these were run

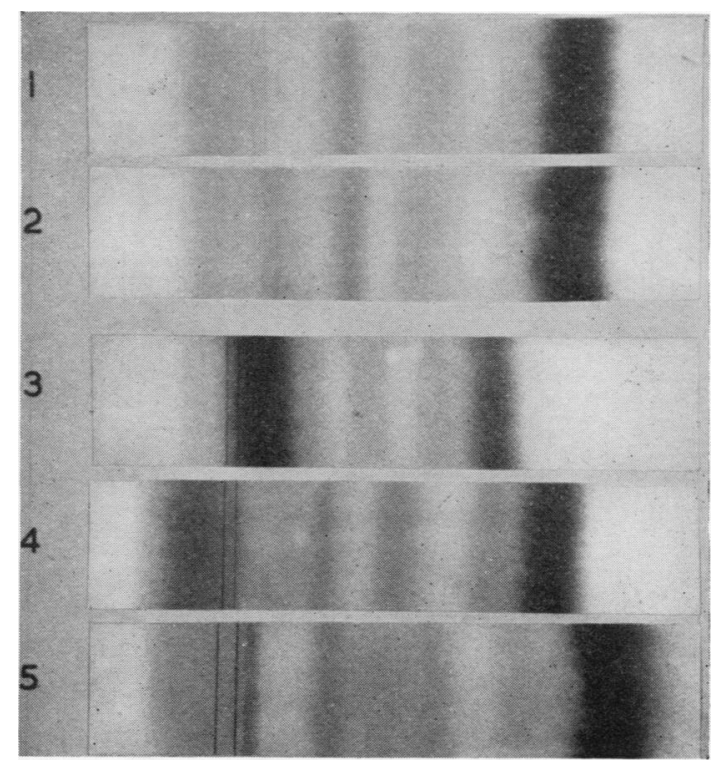

Fig. 2.-Examples of electrophoretograms run in the present apparatus. (1) Normal serum, (2) normal plasma, (3) multiple myeloma serum, (4) chronic lymphatic leukaemia serum, (5) hypercholesterolaemic xanthomatosis serum. 


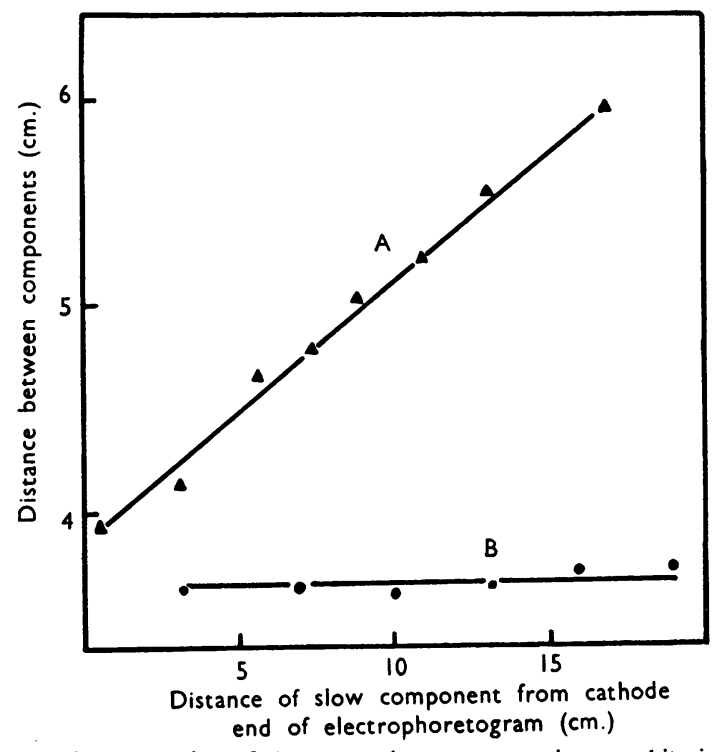

FIG. 3.-Separation of the two main components in egg white in $A$, inverted $V$ apparatus, $B$, present apparatus after electrophoresis in barbitone buffer $p \mathrm{H} 8.6$ for three hours with variation in the point of application of the protein solution to the electrophoretogram.

in $\mathrm{M}-0.05$ barbitone, buffer $p \mathrm{H} 8.6$, and were dyed either with azocarmine B or with bromocresol green. The separated fractions form clear straight bands up to $25 \mathrm{~cm}$. in width, i.e. up to the maximum possible in the apparatus. By comparing the amount of dye eluted from normal serum transferred on to the strip by the ribbon method with that eluted from known volumes of serum applied to the strip by pipette, the amount of serum transferred on to the electrophoretogram from the ribbon in nine minutes is estimated to be about $0.01 \mathrm{ml}$. $/ 0.3$ square $\mathrm{cm}$. of ribbon area.

Electrophoretograms of insulin and parathyroid extract have been obtained. In a large range of buffers a preparation of crystalline insulin (Burroughs Wellcome) ran as a single band. In M-0.05 barbitone buffer $p \mathrm{H} 8.6$ the electrophoretogram of a parathyroid extract (Lilly's " parathormone ") was found to consist of at least three components ; (1) a faint, diffuse, fast-moving band, (2) a band which appeared to be the main component and which was fairly slow-moving, (3) a component which trailed from the main band back to the reference lines. Spun milk and nephrotic urine have also been run successfully.

Many factors affect the extent of electrophoretic movement of protein on filter paper. The principal which may vary are the surrounding temperature, the voltage of the battery, and the duration of electrophoresis. For most purposes in this appara- tus strict control is not necessary since the ratios of movement between the protein fractions have been found to remain constant despite variation in the factors mentioned. Moreover, variation in the position of application of the protein solution to the electrophoretogram was not found to affect the amount of electrophoretic movement. This was demonstrated by laying a band of an egg white preparation diagonally across an electrophoretogram and measuring the distance between the two main components after electrophoresis. As is shown by the lower plot in Fig. 3, the separation of the components was found to remain constant over the whole of the electrophoretogram. When this experiment was repeated on an inverted $V$ apparatus similar to that described by Flynn and de Mayo the distance between the two components was not found to remain constant but, as is seen from the upper plot of Fig. 3, varied with the position of the protein on the electrophoretogram. It follows that comparisons of electrophoretograms run at different times in the inverted $\mathrm{V}$ apparatus is likely to be difficult unless all the factors affecting electrophoretic movement are strictly controlled and standardized. The constancy of the ratios of electrophoretic movement of protein fractions in the present apparatus is illustrated by results obtained from electrophoretograms of five normal sera taken from fasting subjects. These were run at different times with no temperature control and at different voltages in M-0.05 barbitone buffer $p \mathrm{H} 8.6$ on Whatman's No. 1 filter paper. Dextran was included to measure the endo-electro-osmotic flow. Although the distances between the dextran spot and the albumin peak varied from 9 to $15 \mathrm{~cm}$., when this distance was assumed to be 100 in each case, the corresponding distances for the globulin fractions were found to be very constant and were as follows: $81-83,64-66,48-52,17-19$.

\section{Summary}

An apparatus and technique suitable for the filter paper electrophoresis of serum and other proteins is described.

The author is indebted to Dr. J. W. Trevan, F.R.S., for a sample of crystalline insulin and to Dr. A. G. Spencer, G.M., for help in the preparation of this paper.

\section{REFERENCES}

Cremer, H. D., and Tise!ius, A. (1950). Biochem. $Z$., 320, 273. Durrum, E. L. (1950). J. Amer. chem. Soc., 72, 2943

Flynn, F. V. and Mayo, P. de (1951). Lancet, 2. 235.

Kunkel, H. G., and Tiselius, A. (1951). J. gen. Physiol., 35, 89

Pluickthun, H. and Götting, H. (1951). Klin. Wschr., 29, 415 .

Robinson, F. A., and Fehr. K. L. A. (1952). Biochem. J., 51, 298.

Wie!and, T., and Fischer, F. (1948). Naturwissenschaften, 35, 29. 